Article

\title{
DFT Study on Intermetallic Pd-Cu Alloy with Cover Layer Pd as Efficient Catalyst for Oxygen Reduction Reaction
}

\author{
Ji Liu ${ }^{1}$, Xiaofeng Fan ${ }^{2, *}$ (1) , Chang Q. Sun ${ }^{1}$ and Weiguang Zhu ${ }^{1, *}$ \\ 1 Centre for Micro-/Nano-Electronics (NOVITAS), School of Electrical and Electronic Engineering, \\ Nanyang Technological University, 50 Nanyang Avenue, Singapore 639798, Singapore; \\ JLIU024@e.ntu.edu.sg (J.L.); ECQSUN@ntu.edu.sg (C.Q.S.) \\ 2 Key Laboratory of Automobile Materials, Ministry of Education, and College of Materials Science and \\ Engineering, Jilin University, Changchun 130012, China \\ * Correspondence: xffan@jlu.edu.cn (X.F.); ewzhu@ntu.edu.sg (W.Z.); \\ Tel.: +86-431-8516-8444 (X.F.); +65-6790-4541 (W.Z.)
}

Received: 29 November 2017; Accepted: 18 December 2017; Published: 26 December 2017

\begin{abstract}
Detailed density functional theory (DFT) calculations of the adsorption energies ( $\left.E_{a d}\right)$ for oxygen on monolayer $\mathrm{Pd}$ on top of the $\mathrm{Pd}-\mathrm{Cu}$ face-centered cubic (FCC) alloy and intermetallic B2 structure revealed a linear correspondence between the adsorption energies and the $d$-band center position. The calculated barrier $\left(\mathrm{E}_{\text {barrier }}\right)$ for oxygen dissociation depends linearly on the reaction energy difference $(\Delta \mathrm{E})$. The $\mathrm{O}_{2}$ has a stronger adsorption strength and smaller barrier on the intermetallic $\mathrm{Pd}-\mathrm{Cu}$ surface than on its FCC alloy surface. The room-temperature free energy $(\Delta G)$ analysis suggests the oxygen reduction reaction (ORR) pathways proceed by a direct dissociation mechanism instead of hydrogenation into $\mathrm{OOH}$. These results might be of use in designing intermetallic $\mathrm{Pd}-\mathrm{Cu}$ as ORR electrocatalysts.
\end{abstract}

Keywords: ORR; intermetallic; first-principle calculations; surfaces

\section{Introduction}

Proton exchange membrane fuel cells (PEMFCs) have attracted much attention over the last decades due to the advantages of high energy conversion efficiency and the clean energy system [1-3]. Although considerable advances have been achieved in the past years, the obstacles, such as the anode $\mathrm{CO}$ poison issue and sluggish kinetics of the cathode oxygen reduction reaction (ORR), have hindered the widespread applications of fuel cells [4-6]. Platinum (Pt) has the highest catalytic activity for ORR among pure metals. However, the high cost of $\mathrm{Pt}$ and its poor stability and durability are the major drawbacks for the commercialization of Pt-based fuel cells. Previous studies have pointed out that alloying Pt with transition metals can induce Pt-Pt bond compression, resulting in enhanced activity and stability [7-11]. Recently, developing non-Pt catalysts towards fuel cell applications has become a hot topic [12-14]. The potential catalysts must meet the standard of lower cost while exhibiting comparable or even better ORR activity than commercial Pt catalysts. Among the potential catalysts, palladium $(\mathrm{Pd})$ and its alloys have been a popular choice due to the comparatively inexpensive cost and high ORR performance $[13,15,16]$.

Theoretical calculations and experimental results have indicated that $\mathrm{Pd}-\mathrm{M}$ alloys will undergo phase segregations upon annealing at elevated temperature, resulting in a pure Pd overlayer on the bulk alloys, where $\mathrm{M}$ represents transition metals $[16,17]$. Using the $d$-band model proposed by Nórskov et al., the enhanced catalytic activity is explained by the electronic and geometric influence of the alloying element, making the overlayer Pd atoms different from Pd atoms in the bulk [8,18-20]. 
However, the critical problem of this Pd alloy core/shell structure is that the core generally consists of random distributed atoms depending on $\mathrm{Pd} / \mathrm{M}$ ratios, making it difficult to determine and control the active sites experimentally [11,21-23]. Poorer durability in acid than $\mathrm{Pt}$ is also one of the disadvantages limiting the application of Pd-based alloys as cathode materials. Recently, with the development of synthesizing techniques, the intermetallic alloy has been successfully prepared and investigated experimentally, and the intermetallic alloy has enhanced resistance to corrosion and better catalytic activity due to ordered long-range atom distribution [11,24-31]. For example, $\mathrm{Pd}-\mathrm{Cu}$ can undergo the disorder-to-order transformation from FCC to a B2 ordered structure [32]; Pd-Fe can be converted from FCC to the face-centered tetragonal (FCT) ordered phase [5]. However, the understanding of the micro-mechanism is still not clear in detail. In particular, detailed research about the design rule for ORR based on intermetallic alloy is still lacking.

In this work, intermetallic Pd-Cu with monolayer Pd on supporting substrate Pd-Cu alloy (B2 structure) has been proposed and calculated by first principle calculations. It is noted that the monolayer model studied here is not exactly the experimentally synthesized core/shell nanoparticle after phase segregation. Here, with slab model, we focus on the surface reactivity of Pd-Cu alloy with atomic cover layer Pd. We have examined the density of states (DOS) of the compressed Pd monolayer on the intermetallic Pd-Cu and compared with that of FCC alloy Pd-Cu and bulk Pd. An obvious down-shift of the $d$-band center has been witnessed. In order to figure out the relationship between oxygen adsorption energy and ORR activity, the dynamic barrier of oxygen dissociation is explored. By calculating the room temperature free energy change $(\Delta \mathrm{G})$ with the analysis of reaction paths about ORR, we expect that intermetallic $\mathrm{Pd}-\mathrm{Cu}$ can serve as alternate promising cathode materials.

\section{Computational Details}

All the calculations were performed on the basis of spin-polarized density functional theory (DFT) with projector augmented wave (PAW) formalism, as implemented in the Vienna ab initio simulation package (VASP) code [33,34]. The generalized gradient approximation with the parameterization of Predew-Burke-Ernzerh (PBE) was used for the exchange-correlation functional [35,36]. A kinetic energy cutoff of $400 \mathrm{eV}$ for the plane wave expansion with proper $k$-point spacing using Monkhorst-Pack grid method [37] was found to be sufficient to ensure that the total energy was converged at $1 \mathrm{meV} /$ atom level. The convergence criterion for the self-consistence field energy was set to be $10^{-4} \mathrm{eV}$. In this work, we have first built two corresponding unit cells (FCC alloy and B2 intermetallic) and calculated the lattice constants as listed in Table 1 . The Pd/Cu ratio of intermetallic is $50 / 50$, which is proven to be the maximum catalytic activity composition for ORR [38-40]. We have then adopted the same $\mathrm{Pd} / \mathrm{Cu}$ ratio (50/50) for Pd-Cu FCC alloy. The lattice constants $(\mathrm{a}=\mathrm{b}=\mathrm{c}=3.021 \AA$ for intermetallic Pd-Cu B2 structure, $\mathrm{a}=\mathrm{b}=\mathrm{c}=3.811 \AA$ for Pd-Cu FCC alloy) are in accordance with previous experimental results and DFT calculations [41,42]. We have calculated the heats of formation $\left(\Delta \mathrm{H}_{\mathrm{f}}\right)$ for both $\mathrm{Pd}-\mathrm{Cu}$ B2 intermetallic and FCC alloy. The results show that $\mathrm{Pd}-\mathrm{Cu}$ B2 structure $(-13.42 \mathrm{KJ} / \mathrm{mol})$ has lower heats of formation than that of FCC alloy $(-10.93 \mathrm{KJ} / \mathrm{mol})$.

By comparing the ORR activity on these two models (Pd-Cu FCC alloy and B2 intermetallic), we can explore the possible application for intermetallic in fuel cells. When simulating the Pd monolayer on top of two different cores, we have used the slab method by building a pseudomorphic layer, where the lateral lattice spacing is the same as the core. After phase segregation, monolayer Pd is placed on top of four-layer $\mathrm{Pd}-\mathrm{Cu}(111)$ (FCC) or $\mathrm{Pd}-\mathrm{Cu}(110)$ (B2), depending on the unit cell structure. We have chosen (111) surface for FCC alloy and (110) surface for B2 alloy due to the low Miller index, good surface stability and reactivity. The vacuum region is up to $15 \AA$ in order to avoid the spurious coupling effect in $z$ direction. The bottom two layers are fixed with the value of bulk alloy in the structural relaxation. We have adopted $(2 \times 4)$ surface unit cells to represent the sample surface, with minimum coverage up to $1 / 8 \mathrm{ML}$ as shown in Figure 1 . For these models, we have used the following notations: Pd/Pd-Cu(111) represents monolayer Pd on top of Pd-Cu FCC alloy and Pd/Pd-Cu(110) 
represents monolayer $\mathrm{Pd}$ on top of $\mathrm{Pd}-\mathrm{Cu} \mathrm{B} 2$ intermetallic. For reference, we analyzed the adsorption on bulk Pd with five-layer Pd slab along [111] direction which is denoted as $\operatorname{Pd}(111)$ with $(2 \times 2)$ surface unit cell [43]. During the calculation, we have used $4 \times 2 \times 1 k$-point mesh for Pd/Pd-Cu(111), $4 \times 3 \times 1 k$-point mesh for $\mathrm{Pd} / \mathrm{Pd}-\mathrm{Cu}(110)$ and $5 \times 5 \times 1 k$-point mesh for $\mathrm{Pd}(111)$, respectively. We can see that, due to lattice mismatch, the Pd monolayer is compressed with up to $3.49 \%$ to fit bulk Pd-Cu lattice for the $\mathrm{Pd} / \mathrm{Pd}-\mathrm{Cu}(111)$ system. Previous studies by our group and other studies have indicated that this compression effect can partly explain the change of DOS and $d$-band center, which is related to catalytic activity [10,28,43]. For reference, we have built and calculated a five-layer $\mathrm{Pt}(111) \mathrm{slab}$ and $\mathrm{Pt}$ monolayer on top of four-layer $\mathrm{PdCu}(110)$, which are denoted as $\mathrm{Pt}(111)$ and $\mathrm{Pt} / \mathrm{Pd}-\mathrm{Cu}(110)$, respectively. The computational parameters (such as $k$-point mesh) are the same as $\mathrm{Pd} / \mathrm{Pd}-\mathrm{Cu}(110)$ for $\mathrm{Pt} / \mathrm{Pd}-\mathrm{Cu}(110)$ and the same as $\mathrm{Pd}(111)$ for $\mathrm{Pt}(111)$, respectively.

Table 1. The calculated lattice constant for $\mathrm{Pd}-\mathrm{Cu}$ alloy and intermetallic. The added data are from Reference [42] (density functional theory (DFT)) and Reference [41] (Exp.), respectively. Note that $\mathrm{Pd}-\mathrm{Cu}$ alloy has face-centered cubic (FCC) structure while intermetallic $\mathrm{Pd}-\mathrm{Cu}$ has B2 structure.

\begin{tabular}{cccc}
\hline Composition & Structure & Method & $\begin{array}{c}\text { Lattice Constant } \\
\mathbf{a}=\mathbf{b}=\mathbf{c}(\AA)\end{array}$ \\
\hline \multirow{2}{*}{$\mathrm{Pd}$} & \multirow{3}{*}{ FCC } & This work & 3.949 \\
& & DFT & 3.957 \\
& \multirow{3}{*}{ FCC } & Exp. & 3.890 \\
\hline \multirow{2}{*}{$\mathrm{Cu}$} & & This work & 3.633 \\
& & DFT & 3.636 \\
& \multirow{3}{*}{$\mathrm{BdCu}$} & Exp. & 3.615 \\
& & This work & 3.021 \\
& & DFT & 3.026 \\
& \multirow{2}{*}{$\mathrm{FdCu}$} & Exp. & 2.958 \\
& & This work & 3.811 \\
& & DFT & 3.816 \\
& & Exp. & 3.760 \\
\hline
\end{tabular}

(a)
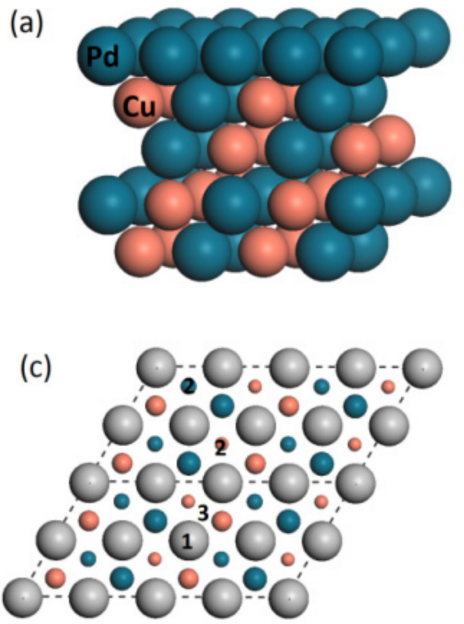

$\mathrm{Cu}$ (b)

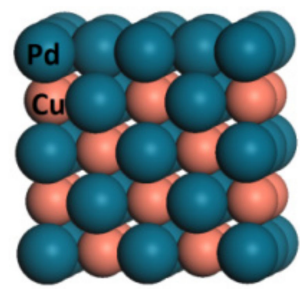

(d)

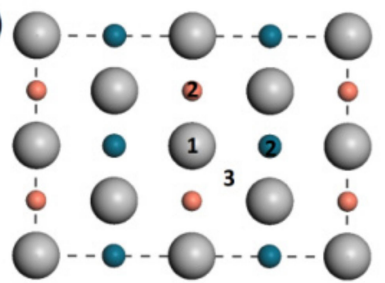

atomic $\mathrm{O} \quad \mathrm{O}_{2}$

1. top $\quad$ 1. top

2. hollow 3. top-bridge-top (tbt)

Figure 1. The configuration of side view of (a) $\mathrm{Pd} / \mathrm{Pd}-\mathrm{Cu}(111)$ alloy and (b) intermetallic $\mathrm{Pd} / \mathrm{Pd}-\mathrm{Cu}(110)$; and top view of (c) $\mathrm{Pd} / \mathrm{Pd}-\mathrm{Cu}(111)$ alloy and (d) intermetallic $\mathrm{Pd} / \mathrm{Pd}-\mathrm{Cu}(110)$. The atomic oxygen adsorption site, $\mathrm{O}_{2}$ adsorption site are shown in Figure 1c,d. Regardless of the atom size, orange color represents $\mathrm{Cu}$ and ashen and dark blue color represent $\mathrm{Pd}$. 
For the adsorption on the surface, the adsorption energy $\left(E_{a d}\right)$ is defined by the formula, $E_{\mathrm{ad}}=E_{\text {tot }}-E_{\text {slab }}-E_{A}$, where $E_{\text {tot }}, E_{\text {slab}}$, and $E_{A}$ are the energies of the slab with adsorbate $A$, isolated slab for the clean metal surface, and isolated adsorbate $\mathrm{A}$, respectively. From the definition, a negative value of $E_{a d}$ corresponds to exothermic adsorption. The nudged elastic band (NEB) method was used to search the minimum energy path and determine the transition state (TS) for $\mathrm{O}_{2}$ dissociation [44].

\section{Results and Discussion}

\subsection{The Adsorption of $\mathrm{O}_{2}$ on $\mathrm{Pd} / \mathrm{PdCu}$ Surface}

Before investigating the possible pathways for ORR, we have first studied the adsorption of atomic $\mathrm{O}$ and dissociation of $\mathrm{O}_{2}$ on Pd overlayer. The adsorption sites are illustrated in Figure $1 \mathrm{c}, \mathrm{d}$ and the results for atomic $\mathrm{O}$ adsorption are listed in Table 2. It is clearly seen that hollow site is more favorable than top site, which is consistent with previous DFT studies [16,45]. There are two kinds of hollow sites: hollow_Pd (top view) and hollow_Cu (top view). Here, we have calculated the adsorption energies on both hollow sites, and the results show that the adsorption energies only have a negligible difference (about $0.1 \mathrm{eV}$ ). The adsorption energy for the top site is positive, indicating that the adsorption is endothermic. DFT calculations by Tang et al. indicates that $\mathrm{Cu}$ atoms can reduce the $\mathrm{Pd}-\mathrm{O}$ binding energy [46]. From Table 2, it is clearly seen that, by alloying, the adsorption strength of oxygen is reduced compared with that of $\operatorname{Pd}(111)$ surface.

Table 2. The calculated $d$-band center $\left(\varepsilon_{d}\right)$, adsorption energies of atomic $\mathrm{O}\left(\mathrm{E}_{\mathrm{O}}\right)$ and $\mathrm{O}_{2}\left(\mathrm{E}_{\mathrm{O} 2}\right)$ and key parameters for $\mathrm{O}_{2}$ dissociation process including bond length, activation energy $(\Delta \mathrm{E})$ and energy barrier $\left(\mathrm{E}_{\text {barrier }}\right)$. Note that the energy of atomic oxygen is defined as the half of that of $\mathrm{O}_{2}$. For $\mathrm{O}_{2}$ dissociation process, the initial state (IS) corresponds to the most stable $\mathrm{O}_{2}$ adsorption, the final states (FS) corresponds to two separate atomic oxygen atoms adsorption and the transition state (TS) is obtained by NEB calculations. We have added the data of $\operatorname{Pt}(111)$ from Reference $[16,45]$.

\begin{tabular}{|c|c|c|c|c|c|c|c|}
\hline \multirow{3}{*}{ Composition } & \multirow{3}{*}{$\begin{array}{c}d \text {-Band } \\
\text { Center } \\
(\mathrm{eV})\end{array}$} & \multicolumn{3}{|c|}{ Adsorption Energy } & \multirow{3}{*}{$\begin{array}{c}\text { Bond } \\
\text { Length } \\
\text { O-O (̊̊) }\end{array}$} & \multirow{2}{*}{\multicolumn{2}{|c|}{$\mathrm{O}_{2}$ Dissociation $(\mathrm{eV})$}} \\
\hline & & \multicolumn{2}{|c|}{$E_{O}(e V)$} & \multirow{2}{*}{$\frac{\mathrm{E}_{\mathrm{O} 2}(\mathrm{eV})}{\mathrm{tbt}}$} & & & \\
\hline & & Hollow & Top & & & $\Delta \mathrm{E}=\mathrm{E}_{\mathrm{FS}}-\mathrm{E}_{\mathrm{IS}}$ & $\mathrm{E}_{\text {barrier }}=\mathrm{E}_{\mathrm{TS}}-\mathrm{E}_{\mathrm{IS}}$ \\
\hline $\mathrm{Pt} / \mathrm{Pd}-\mathrm{Cu}(110)$ & -2.66 & -0.63 & Unstable & -0.95 & 1.362 & -0.36 & 1.29 \\
\hline $\mathrm{Pd} / \mathrm{Pd}-\mathrm{Cu}(111)$ & -2.12 & -1.02 & 0.26 & -0.36 & 1.341 & -0.77 & 0.82 \\
\hline $\mathrm{Pd} / \mathrm{Pd}-\mathrm{Cu}(110)$ & -1.93 & -1.18 & 0.31 & -0.73 & 1.340 & -1.34 & 0.60 \\
\hline $\operatorname{Pd}(111)$ & -1.86 & -1.23 & - & -1.18 & 1.342 & -0.96 & 0.70 \\
\hline $\operatorname{Pt}(111)^{\text {Reference }}$ & -2.19 & -0.85 & - & -0.62 & - & -0.86 & 0.77 \\
\hline
\end{tabular}

In order to understand the adsorption trend and details of bond formation on the surface, we have analyzed the electronic properties by calculating the density of states (DOS). The partial DOS (PDOS) is shown in Figure 2. Due to phase transformation, the PDOS shape of Pd monolayer on intermetallic $\mathrm{Pd}-\mathrm{Cu}$ (B2 structure) is different from that of FCC Pd overlayer. The localized DOS near the Fermi level of surface Pd overlayer are considered to be related to the adsorption strength. Pt monolayer on intermetallic Pd-Cu has the least localized DOS near the Fermi level and Pd monolayer on intermetallic Pd-Cu has the highest localized DOS. This sequence is in good agreement with the adsorption trend. In order to study the strain effect, we have built and calculated a compressed $\mathrm{Pd}(111)$ with five-layer slab along [111] direction, which has the same stain as $\mathrm{Pd} / \mathrm{Pd}-\mathrm{Cu}(111)$. From Figure 2c, d, we can clearly see that the DOS are modified by both strain effect due to lattice mismatch and charge transfer between the substrate and Pd monolayer. In order to understand the charge transfer between the substrate and Pd monolayer, we have estimated the electron transfer by calculating the difference of number of electrons for $\mathrm{Pd}$ monolayer with and without the substrate for $\mathrm{Pd} / \mathrm{Pd}-\mathrm{Cu}(111)$ and compressed $\mathrm{Pd}(111)$. This is obtained by integrating the DOS of Pd monolayer. For compressed Pd(111), the estimated electron transfer from substrate to $\mathrm{Pd}$ surface is 0.22 electron per atom; for $\mathrm{Pd} / \mathrm{Pd}-\mathrm{Cu}(111)$, the estimated electron transfer from substrate to Pd monolayer is 0.33 electron per atom. Upon alloying, 
the positions of $d$-band center $\left(\varepsilon_{d}\right)$ shift downwards (away from the Fermi level). This downward shifting is related to the change of adsorption energy on various Pd surfaces. As shown in Table 2, the $d$-band center of $\operatorname{Pd}(111)$ is $-1.86 \mathrm{eV}$, which is supported by previous reports [47]. The calculated $d$-band center for compressed $\mathrm{Pd}(111)$ is $-2.02 \mathrm{eV}$, which is located between $\mathrm{Pd}(111)(-1.86 \mathrm{eV})$ and $\mathrm{Pd} / \mathrm{Pd}(111)(-2.12 \mathrm{eV})$. This is in accordance with the corresponding trend of localized PDOS near Fermi level and the estimated electron transfer from the substrate. Previous DFT calculations have revealed that insertion of $\mathrm{Cu}$ atoms in Pd lattice affects geometric and electronic properties of Pd [48]. An obviously linear relationship between $d$-band center $\left(\varepsilon_{d}\right)$ and atomic oxygen adsorption energy $\left(E_{O}\right)$ is witnessed and shown in Figure $3 a$, where we have added some data from other studies for better understanding $[16,45]$. This linear relationship is supported by $d$-band center model proposed by Nórskov et al., which is widely applied in understanding the bond formation and activity trend among transition metals $[49,50]$.
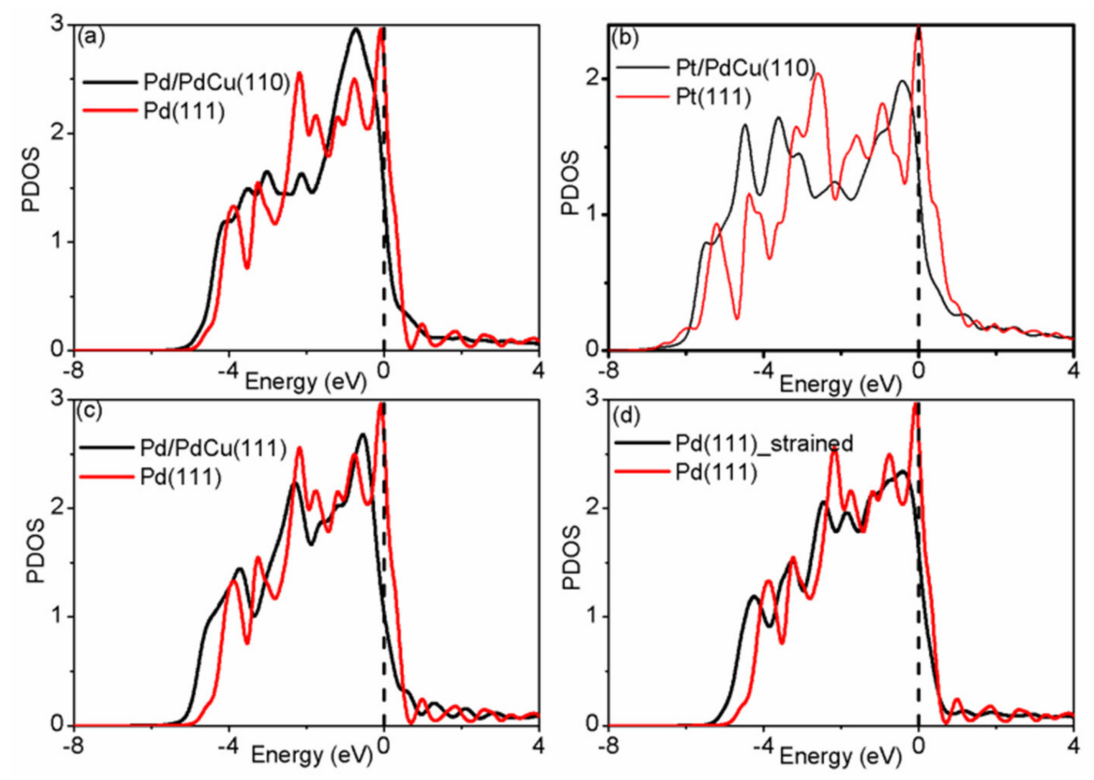

Figure 2. The calculated partial density of states (PDOS) for (a) Pd monolayer on top of intermetallic $\mathrm{Pd}-\mathrm{Cu}$; (b) Pt monolayer on top of intermetallic $\mathrm{Pd}-\mathrm{Cu}$; (c) Pd monolayer on top of Pd-Cu FCC alloy, and (d) compressed $\mathrm{Pd}(111)$. Noted that $\mathrm{Pd} / \mathrm{Pd}-\mathrm{Cu}(111)$ and compressed $\mathrm{Pd}(111)$ have the same strain up to $3.49 \%$.
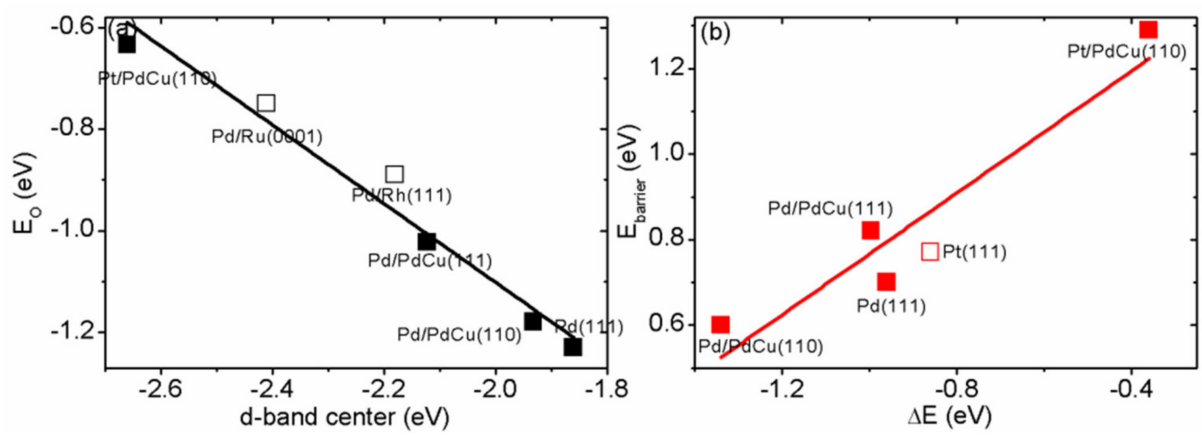

Figure 3. The calculated (a) adsorption energy of atomic $\mathrm{O}$ as a function of the $d$-band center of surface Pd relative to Fermi level (marked with black solid square) and (b) plot of Brǿnsted-Evans-Polanyi relations for $\mathrm{O}_{2}$ dissociation (marked with red solid square). The red solid line is the fitting line with the equation $\mathrm{E}_{\text {barrier }}=0.714 \times \Delta \mathrm{E}+1.479$. The added data in Figure 3a (marked with black empty square) are from Reference [16] and the added date in Figure 3b (marked with red empty square) is from Reference [45], respectively. 


\subsection{The Dissociation of $\mathrm{O}_{2}$ on $\mathrm{Pd} / \mathrm{PdCu}$ Surface}

For the adsorption of $\mathrm{O}_{2}$, our previous paper and other studies have pointed out that the top-bridge-top (tbt) site is more stable and favored on metal surfaces compared with top site $[43,45]$. Here, we have calculated the adsorption energies on both the tbt site and top site, which results in the same conclusion as previous reports. Thus, in this work, the oxygen (gas) is initially placed on the tbt site. The calculated results are shown in Table 2. Upon being adsorbed on Pd surface, the O-O bond length is almost the same value as the various Pd surfaces. However, the $\mathrm{O}_{2}$ adsorbed on $\mathrm{Pt}$ monolayer has a larger $\mathrm{O}-\mathrm{O}$ bond length of up to $1.362 \AA$. The adsorption energies of $\mathrm{O}_{2}$ on various $\mathrm{Pd}$ surfaces also follow the linear trend with respect to $d$-band center $\left(\varepsilon_{d}\right)$. These chemisorbed $\mathrm{O}_{2}$ can serve as precursors for ORR. Generally, two possible reaction mechanisms for the surface reaction of chemisorbed $\mathrm{O}_{2}$ are direct dissociation and hydrogenation into $\mathrm{OOH}$ [51]. Here, we will first consider the direct dissociation mechanism as the next step to investigate the ORR activity, where the dissociative barrier $\left(\mathrm{E}_{\text {barrier }}\right)$ is regarded as an indicator to ORR activity. We will discuss the possibility of hydrogenation into $\mathrm{OOH}$ in the next section. The initial state (IS) is $\mathrm{O}_{2}$ chemisorbed on Pd surface, and the final state (FS) is two separated oxygen atoms occupied on hollow site. The nudged elastic band (NEB) method was performed to search for the transition state (TS) and the energy barrier of dissociation [44]. The top view of selected states along the dissociation path are shown in Figure 4. It is clearly seen that the $\mathrm{O}_{2}$ precursor will rotate from tbt site at the beginning to reach the transition state, where the two oxygen atoms are stretched to opposite direction gradually. The distance will continue to be enlarged until reaching the final state. As shown in Table 2, $\mathrm{O}_{2}$ chemisorbed on $\mathrm{Pd}$ monolayer on top of intermetallic Pd-Cu can be easily dissociated with energy barrier as low as $0.60 \mathrm{eV}$, while the dissociation of $\mathrm{O}_{2}$ on Pt monolayer on top of intermetallic $\mathrm{Pd}-\mathrm{Cu}$ is unfavorable at room temperature with an energy barrier as high as $1.29 \mathrm{eV}$. It is noted that the energy barrier for $\mathrm{Pd} / \mathrm{Pd}-\mathrm{Cu}(110)$ is smaller than that of $\mathrm{Pd} / \mathrm{Pd}-\mathrm{Cu}(111)$, which can serve as evidence of enhanced ORR activity for intermetallic observed experimentally [32].

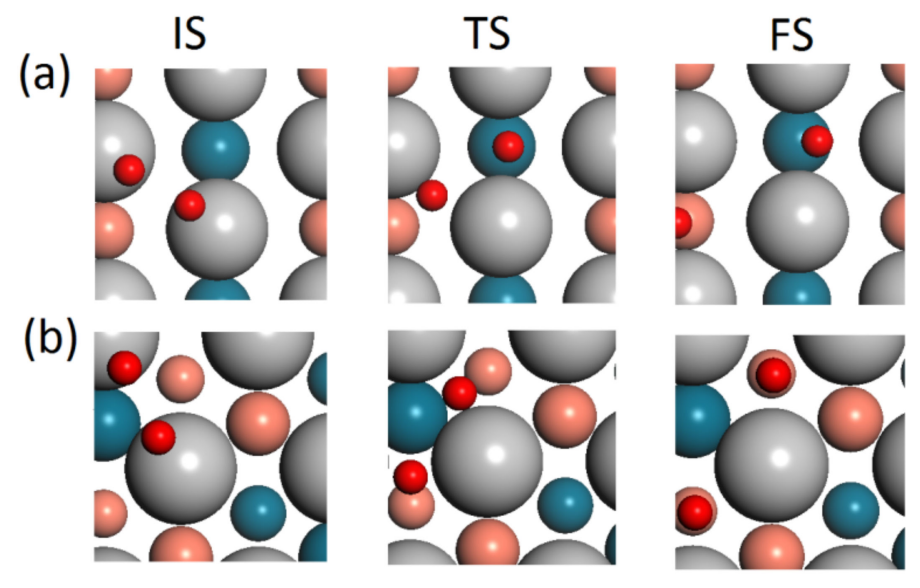

Figure 4. The top view of selected states along the path of $\mathrm{O}_{2}$ dissociation for (a) intermetallic $\mathrm{Pd}-\mathrm{Cu}$ $\mathrm{Pd} / \mathrm{Pd}-\mathrm{Cu}(110)$ and (b) Pd-Cu FCC alloy $\mathrm{Pd} / \mathrm{Pd}-\mathrm{Cu}(111)$.

In order to figure out the universal trend and the design rule for ORR, we have plotted the well-known Brǿnsted-Evans-Polanyi (BEP) relations as shown in Figure 3b. We have added the data of $\mathrm{Pt}(111)$ for better understanding [45]. A linear relationship between the energy barrier $\left(\mathrm{E}_{\mathrm{barrier}}\right)$ and reaction energy difference $\left(\Delta \mathrm{E}=\mathrm{E}_{\mathrm{FS}}-\mathrm{E}_{\mathrm{IS}}\right)$ is observed. This linear correlation is the direct evidence that intermetallic $\mathrm{Pd}-\mathrm{Cu}$ with $\mathrm{Pd}$ monolayer can serve as an alternate cathode material for fuel cell applications. The fitted line for oxygen dissociation is $\mathrm{E}_{\mathrm{barrier}}=0.714 \times \Delta \mathrm{E}+1.479$. We can see that larger reaction energy difference can result in smaller energy barrier. The reaction energy difference 
is related to both adsorption energy for reactants and products. This is why too weak or too strong adsorption is not suitable for heterogeneous catalysis, which is also known as Sabatier principle [50].

\subsection{The Potential Pathway of ORR on Intermetallic $\mathrm{Pd} / \mathrm{Pd}-\mathrm{Cu}(110)$}

Since intermetallic $\mathrm{Pd}-\mathrm{Cu}$ is very promising for fuel cell applications, we will then explore the thermodynamics of the cathode reaction for intermetallic $\mathrm{Pd}-\mathrm{Cu}$. Generally, the cathode reaction is processed as follows: the adsorbed oxygen will react with $\mathrm{H}^{+}$species into $\mathrm{H}_{2} \mathrm{O}$.

$$
1 / 2 \mathrm{O}_{2}+2\left(\mathrm{H}^{+}+\mathrm{e}^{-}\right) \rightarrow \mathrm{H}_{2} \mathrm{O}
$$

As discussed in the previous section, the two possible reaction pathways for surface reaction of $\mathrm{O}_{2}$ are direct dissociation or hydrogenation into $\mathrm{OOH}$ species. Here, we will explore the possibility of hydrogenation into $\mathrm{OOH}$ by considering the reaction energy difference $\left(\Delta \mathrm{E}=\mathrm{E}_{\mathrm{FS}}-\mathrm{E}_{\mathrm{IS}}\right)$. The results are summarized in Table 3. We can see that the possibility of hydrogenation into $\mathrm{OOH}$ is extremely low due to thermodynamically unfavorable. Besides this, the adsorbed $\mathrm{OOH}$ species may directly dissociate into $\mathrm{O}+\mathrm{OH}$ on the catalyst surface.

Table 3. The calculated reaction energy difference $(\Delta \mathrm{E})$ for adsorbed $\mathrm{O}_{2}$ hydrogenation to $\mathrm{OOH}$. It can be seen that $\mathrm{OOH}$ species may dissociate into $\mathrm{O}+\mathrm{OH}$. The reaction energy difference is calculated by $\Delta \mathrm{E}=\mathrm{E}_{\mathrm{FS}}-\mathrm{E}_{\mathrm{IS}}$.

\begin{tabular}{cc}
\hline Reaction Step & Reaction Energy Difference $\Delta \mathbf{E}(\mathbf{e V})$ \\
\hline $\mathrm{O}_{2}{ }^{*}+\mathrm{H}^{+}+\mathrm{e}^{-} \rightarrow \mathrm{OOH}^{*}$ & -0.001 \\
$\mathrm{OOH}^{*} \rightarrow \mathrm{O}^{*}+\mathrm{OH}^{*}$ & -0.011 \\
\hline
\end{tabular}

Next, in order to investigate a complete cathode reaction pathway, we will investigate two possible reaction pathways as represented by reaction pathway I and reaction pathway II, where * denotes a vacant site on the surface.

Reaction pathway I

$$
\begin{gathered}
1 / 2 \mathrm{O}_{2}+{ }^{*} \rightarrow \mathrm{O}^{*} \\
\mathrm{O}^{*}+\mathrm{H}^{+}+\mathrm{e}^{-} \rightarrow \mathrm{OH}^{*} \\
\mathrm{OH}^{*}+\mathrm{H}^{+}+\mathrm{e}^{-} \rightarrow \mathrm{H}_{2} \mathrm{O}
\end{gathered}
$$

Reaction pathway II

$$
\begin{gathered}
\mathrm{O}_{2}+{ }^{*} \rightarrow \mathrm{O}_{2}^{*} \\
\mathrm{O}_{2}^{*}+\mathrm{H}^{+}+\mathrm{e}^{-} \rightarrow \mathrm{OOH}^{*} \\
\mathrm{OOH}^{*}+\mathrm{H}^{+}+\mathrm{e}^{-} \rightarrow \mathrm{O}^{*}+\mathrm{H}_{2} \mathrm{O} \\
\mathrm{O}^{*}+\mathrm{H}^{+}+\mathrm{e}^{-} \rightarrow \mathrm{OH}^{*} \\
\mathrm{OH}^{*}+\mathrm{H}^{+}+\mathrm{e}^{-} \rightarrow \mathrm{H}_{2} \mathrm{O}
\end{gathered}
$$

We have plotted the reaction energy diagram for the two reaction pathways in Figure 5. For the final step, the adsorption energy of $\mathrm{H}_{2} \mathrm{O}$ is only $-0.13 \mathrm{eV} . \mathrm{H}_{2} \mathrm{O}$ molecule can diffuse freely from the surface. The surface is therefore ready to perform the next catalytic cycle. It is noted that, for reaction pathway II, hydrogenation to $\mathrm{OOH}$ (step $2 \mathrm{~b}$ ) is energetically unfavorable. However, the overall reaction is favorable. 

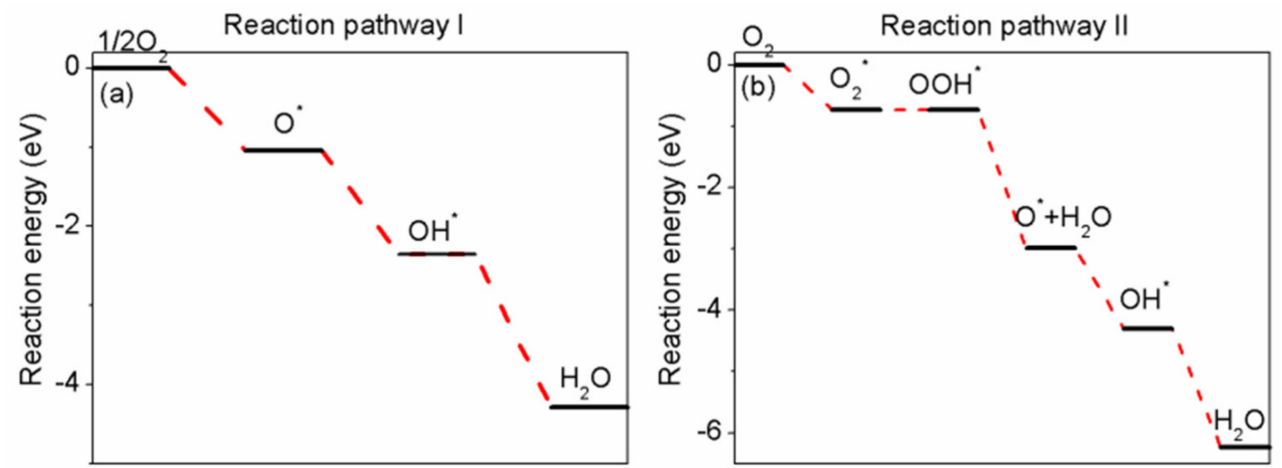

Figure 5. The reaction energy diagram on $\mathrm{Pd} / \mathrm{Pd}-\mathrm{Cu}(110)$ surface of (a) reaction pathway I and (b) reaction pathway II.

We will then focus on reaction path I and calculate the free energies of the intermediates by the formula $\Delta \mathrm{G}=\Delta \mathrm{E}+\Delta \mathrm{G}_{\mathrm{U}}+\Delta \mathrm{ZPE}-\mathrm{T} \Delta \mathrm{S}$ [52], where $\Delta \mathrm{E}$ is the reaction energy from DFT calculations of adsorbed reactants or intermediates; $\Delta \mathrm{G}_{\mathrm{U}}$ (equal to $-\mathrm{eU}, \mathrm{U}$ is the electrode potential) is the relevant bias effect due to electron and proton transfer; $\triangle \mathrm{ZPE}$ and $\Delta \mathrm{S}$ are the zero point energy difference and the entropy difference between the adsorbed state and the gas phase, respectively; and $\mathrm{T}$ is the system temperature ( $\mathrm{T}=298.15 \mathrm{~K}$ in this work). The zero-point energy difference is obtained by DFT calculations of vibration frequencies of adsorbates. We have set the $\mathrm{pH}$ value to be zero. At a $\mathrm{pH}$ different from zero, we can correct the free energy by adding the free energy contributions due to variations in $\mathrm{H}^{+}$concentration $\Delta \mathrm{G}_{\mathrm{pH}}$. The chemical potential of a proton/electron $\left(\mathrm{H}^{+}+\mathrm{e}^{-}\right)$is equal to half of that of a gas-phase $\mathrm{H}_{2}$. The hydrogen atom is with reference to half of gas-phase $\mathrm{H}_{2}$; the oxygen atom is with reference to half of gas-phase $\mathrm{O}_{2}$. The Gibbs free energy diagram is shown in Figure 6, where we have considered potential effect. When the potential equals to $1.29 \mathrm{~V}$, the connecting line for step (3a) is horizontal. Higher than this critical potential value (1.29 V), both step (2a) and step (3a) will become uphill.

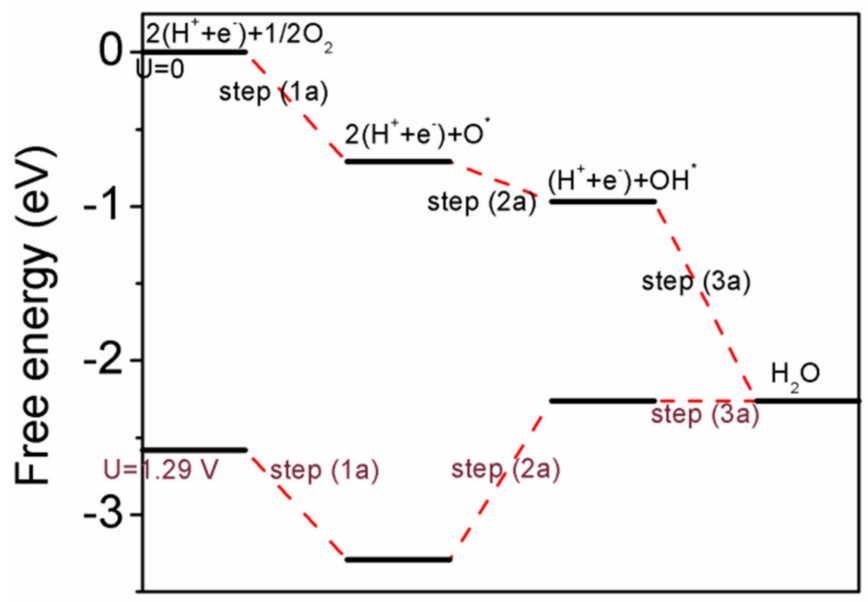

Figure 6. The free energy diagram for oxygen reduction on $\mathrm{Pd} / \mathrm{Pd}-\mathrm{Cu}(110)$ surface. It is noted that if the potential is higher than $1.29 \mathrm{~V}$, step (2a) and step (3a) will become uphill.

\section{Conclusions}

With first principle calculations, we have investigated the potential of the intermetallic $\mathrm{Pd}-\mathrm{Cu}$ alloy as electrocatalyst for ORR and the corresponding reaction mechanisms. On the basis of $d$-band model, we have calculated the adsorption energies $\left(\mathrm{E}_{\mathrm{ad}}\right)$ on Pd monolayer on top of various cores. The stronger adsorption strength on $\mathrm{Pd} / \mathrm{Pd}-\mathrm{Cu}(110)$ is attributed to both strain effect due to lattice mismatch 
and charge transfer from the substrate. We have then evaluated the oxygen dissociation barrier $\left(\mathrm{E}_{\text {barrier }}\right)$ as an indicator to ORR activity by the nudged elastic band (NEB) method. The calculated barrier increases, following the order $\mathrm{Pd} / \mathrm{Pd}-\mathrm{Cu}(110)<\mathrm{Pt}(111)<\mathrm{Pd} / \mathrm{Pd}-\mathrm{Cu}(111)$. By plotting the Brónsted-Evans-Polanyi (BEP) relations, the intermetallic $\mathrm{Pd}-\mathrm{Cu}$ with atomic cover layer Pd is found to have promising adsorbate-surface interaction. The proposed pathway for ORR indicates that adsorbed oxygen will go through direct dissociation mechanism rather than hydrogenation to $\mathrm{OOH}$ species. The following pathways, including $\mathrm{O}^{*}+\mathrm{H}^{+}+\mathrm{e}^{-} \rightarrow \mathrm{OH}^{*}$ and $\mathrm{OH}^{*}+\mathrm{H}^{+}+\mathrm{e}^{-} \rightarrow \mathrm{H}_{2} \mathrm{O}$, are found to be thermodynamically favorable. With these results, it is believed that the intermetallic $\mathrm{Pd}-\mathrm{Cu}$ alloy with cover layer Pd may be an attractive alternate cathode material.

Acknowledgments: The authors would like to acknowledge the support by the National Key R\&D Development Program of China (Grant No. 2016YFA0200400), Nanyang Technological University under Grant No. RG97/15 and RG101/14, and the National Natural Science Foundation of China (Grant No. 11504123 and No. 51627805).

Author Contributions: J.L. did first principles calculations; J.L., X.F. contributed to the concept and analysis of results; J.L., X.F., C.Q.S. and W.Z. participated in drafting the manuscript.

Conflicts of Interest: The authors declare no conflict of interest.

\section{References}

1. Luo, M.; Sun, Y.; Wang, L.; Guo, S. Tuning Multimetallic Ordered Intermetallic Nanocrystals for Efficient Energy Electrocatalysis. Adv. Energy Mater. 2017, 7. [CrossRef]

2. Wang, L.; Zeng, Z.; Ma, C.; Liu, Y.; Giroux, M.; Chi, M.; Jin, J.; Greeley, J.; Wang, C. Plating Precious Metals on Nonprecious Metal Nanoparticles for Sustainable Electrocatalysts. Nano Lett. 2017, 17, 3391-3395. [CrossRef] [PubMed]

3. Mahata, A.; Rawat, K.S.; Choudhuri, I.; Pathak, B. Single-layered platinum nanocage: A highly selective and efficient catalyst for fuel cells. J. Mater. Chem. A 2016, 4, 12756-12767. [CrossRef]

4. $\quad$ Chung, D.Y.; Jun, S.W.; Yoon, G.; Kwon, S.G.; Shin, D.Y.; Seo, P.; Yoo, J.M.; Shin, H.; Chung, Y.-H.; Kim, H. Highly durable and active PtFe nanocatalyst for electrochemical oxygen reduction reaction. J. Am. Chem. Soc. 2015, 137, 15478-15485. [CrossRef] [PubMed]

5. Jiang, G.; Zhu, H.; Zhang, X.; Shen, B.; Wu, L.; Zhang, S.; Lu, G.; Wu, Z.; Sun, S. Core/shell face-centered tetragonal FePd/Pd nanoparticles as an efficient non-Pt catalyst for the oxygen reduction reaction. ACS Nano 2015, 9, 11014-11022. [CrossRef] [PubMed]

6. Lang, X.Y.; Han, G.F.; Xiao, B.B.; Gu, L.; Yang, Z.Z.; Wen, Z.; Zhu, Y.F.; Zhao, M.; Li, J.C.; Jiang, Q. Mesostructured Intermetallic Compounds of Platinum and Non-Transition Metals for Enhanced Electrocatalysis of Oxygen Reduction Reaction. Adv. Funct. Mater. 2015, 25, 230-237. [CrossRef]

7. Shao, M.; Shoemaker, K.; Peles, A.; Kaneko, K.; Protsailo, L. Pt monolayer on porous Pd-Cu alloys as oxygen reduction electrocatalysts. J. Am. Chem. Soc. 2010, 132, 9253-9255. [CrossRef] [PubMed]

8. Stamenkovic, V.; Mun, B.S.; Mayrhofer, K.J.; Ross, P.N.; Markovic, N.M.; Rossmeisl, J.; Greeley, J.; Nørskov, J.K. Changing the activity of electrocatalysts for oxygen reduction by tuning the surface electronic structure. Angew. Chem. 2006, 118, 2963-2967. [CrossRef]

9. Prabhudev, S.; Bugnet, M.; Bock, C.; Botton, G.A. Strained lattice with persistent atomic order in $\mathrm{Pt}_{3} \mathrm{Fe}_{2}$ intermetallic core-shell nanocatalysts. ACS Nano 2013, 7, 6103-6110. [CrossRef] [PubMed]

10. Zhang, S.; Zhang, X.; Jiang, G.; Zhu, H.; Guo, S.; Su, D.; Lu, G.; Sun, S. Tuning nanoparticle structure and surface strain for catalysis optimization. J. Am. Chem. Soc. 2014, 136, 7734-7739. [CrossRef] [PubMed]

11. Wang, D.; Yu, Y.; Xin, H.L.; Hovden, R.; Ercius, P.; Mundy, J.A.; Chen, H.; Richard, J.H.; Muller, D.A.; DiSalvo, F.J. Tuning oxygen reduction reaction activity via controllable dealloying: A model study of ordered $\mathrm{Cu}_{3} \mathrm{Pt} / \mathrm{C}$ intermetallic nanocatalysts. Nano Lett. 2012, 12, 5230-5238. [CrossRef] [PubMed]

12. Gawande, M.B.; Goswami, A.; Asefa, T.; Guo, H.; Biradar, A.V.; Peng, D.-L.; Zboril, R.; Varma, R.S. Core-shell nanoparticles: Synthesis and applications in catalysis and electrocatalysis. Chem. Soc. Rev. 2015, 44, 7540-7590. [CrossRef] [PubMed]

13. Kuttiyiel, K.A.; Sasaki, K.; Su, D.; Wu, L.; Zhu, Y.; Adzic, R.R. Gold-promoted structurally ordered intermetallic palladium cobalt nanoparticles for the oxygen reduction reaction. Nat. Commun. 2014, 5, 5185. [CrossRef] [PubMed] 
14. Chen, Z.Z.; Zhang, X.; Lu, G. Multiscale Computational Design of Core/Shell Nanoparticles for Oxygen Reduction Reaction. J. Phys. Chem. C 2017, 121, 1964-1973. [CrossRef]

15. Xiao, W.; Cordeiro, M.A.L.; Gong, M.; Han, L.; Wang, J.; Bian, C.; Zhu, J.; Xin, H.L.; Wang, D. Optimizing the ORR activity of Pd based nanocatalysts by tuning their strain and particle size. J. Mater. Chem. A 2017. [CrossRef]

16. Shao, M.; Liu, P.; Zhang, J.; Adzic, R. Origin of enhanced activity in palladium alloy electrocatalysts for oxygen reduction reaction. J. Phys. Chem. B 2007, 111, 6772-6775. [CrossRef] [PubMed]

17. Ruban, A.; Skriver, H.L.; Nørskov, J.K. Surface segregation energies in transition-metal alloys. Phys. Rev. B 1999, 59, 15990. [CrossRef]

18. Nørskov, J.K.; Abild-Pedersen, F.; Studt, F.; Bligaard, T. Density functional theory in surface chemistry and catalysis. Proc. Natl. Acad. Sci. USA 2011, 108, 937-943. [CrossRef] [PubMed]

19. Hammer, B.; Nørskov, J.K. Theoretical surface science and catalysis-Calculations and concepts. Adv. Catal. 2000, 45, 71-129.

20. Mao, Y.; Wang, H.F.; Hu, P. Theory and applications of surface micro-kinetics in the rational design of catalysts using density functional theory calculations. Wiley Interdiscip. Rev. Comput. Mol. Sci. 2017, 7. [CrossRef]

21. Wang, C.; Sang, X.; Gamler, J.T.; Chen, D.P.; Unocic, R.R.; Skrabalak, S.E. Facet-Dependent Deposition of Highly Strained Alloyed Shells on Intermetallic Nanoparticles for Enhanced Electrocatalysis. Nano Lett. 2017, 17, 5526-5532. [CrossRef] [PubMed]

22. Wang, D.; Yu, Y.; Zhu, J.; Liu, S.; Muller, D.A.; Abruña, H.C.D. Morphology and activity tuning of Cu 3 Pt/C ordered intermetallic nanoparticles by selective electrochemical dealloying. Nano Lett. 2015, 15, 1343-1348. [CrossRef] [PubMed]

23. Zhang, L.; Henkelman, G. Tuning the oxygen reduction activity of Pd shell nanoparticles with random alloy cores. J. Phys. Chem. C 2012, 116, 20860-20865. [CrossRef]

24. Antolini, E. Alloy vs. intermetallic compounds: Effect of the ordering on the electrocatalytic activity for oxygen reduction and the stability of low temperature fuel cell catalysts. Appl. Catal. B 2017, 217, 201-213. [CrossRef]

25. Arumugam, B.; Tamaki, T.; Yamaguchi, T. Beneficial role of copper in the enhancement of durability of ordered intermetallic PtFeCu catalyst for electrocatalytic oxygen reduction. ACS Appl. Mater. Interfaces 2015, 7, 16311-16321. [CrossRef] [PubMed]

26. Du, X.X.; He, Y.; Wang, X.X.; Wang, J.N. Fine-grained and fully ordered intermetallic PtFe catalysts with largely enhanced catalytic activity and durability. Energy Environ. Sci. 2016, 9, 2623-2632. [CrossRef]

27. Yan, Y.; Du, J.S.; Gilroy, K.D.; Yang, D.; Xia, Y.; Zhang, H. Intermetallic Nanocrystals: Syntheses and Catalytic Applications. Adv. Mater. 2017. [CrossRef] [PubMed]

28. Wang, G.; Huang, B.; Xiao, L.; Ren, Z.; Chen, H.; Wang, D.; Abruña, H.D.; Lu, J.; Zhuang, L. Pt skin on AuCu intermetallic substrate: A strategy to maximize Pt utilization for fuel cells. J. Am. Chem. Soc. 2014, 136, 9643-9649. [CrossRef] [PubMed]

29. Wang, D.; Xin, H.L.; Hovden, R.; Wang, H.; Yu, Y.; Muller, D.A.; DiSalvo, F.J.; Abruña, H.D. Structurally ordered intermetallic platinum-cobalt core-shell nanoparticles with enhanced activity and stability as oxygen reduction electrocatalysts. Nat. Mater. 2013, 12, 81-87. [CrossRef] [PubMed]

30. Gschneidner, K.; Ji, M.; Wang, C.; Ho, K.; Russell, A.; Mudryk, Y.; Becker, A.; Larson, J. Influence of the electronic structure on the ductile behavior of B2 CsCl-type AB intermetallics. Acta Mater. 2009, 57, 5876-5881. [CrossRef]

31. Chi, M.; Wang, C.; Lei, Y.; Wang, G.; Li, D.; More, K.L.; Lupini, A.; Allard, L.F.; Markovic, N.M.; Stamenkovic, V.R. Surface faceting and elemental diffusion behaviour at atomic scale for alloy nanoparticles during in situ annealing. Nat. Commun. 2015, 6. [CrossRef] [PubMed]

32. Wang, C.; Chen, D.P.; Sang, X.; Unocic, R.R.; Skrabalak, S.E. Size-Dependent Disorder-Order Transformation in the Synthesis of Monodisperse Intermetallic PdCu Nanocatalysts. ACS Nano 2016, 10, 6345-6353. [CrossRef] [PubMed]

33. Kresse, G.; Furthmüller, J. Efficient iterative schemes for Ab initio total-energy calculations using a plane-wave basis set. Phys. Rev. B 1996, 54, 11169. [CrossRef]

34. Kresse, G.; Joubert, D. From ultrasoft pseudopotentials to the projector augmented-wave method. Phys. Rev. B 1999, 59, 1758. [CrossRef] 
35. Perdew, J.P.; Chevary, J.A.; Vosko, S.H.; Jackson, K.A.; Pederson, M.R.; Singh, D.J.; Fiolhais, C. Atoms, molecules, solids, and surfaces: Applications of the generalized gradient approximation for exchange and correlation. Phys. Rev. B 1992, 46, 6671. [CrossRef]

36. Perdew, J.P.; Burke, K.; Ernzerhof, M. Generalized gradient approximation made simple. Phys. Rev. Lett. 1996, 77, 3865. [CrossRef] [PubMed]

37. Monkhorst, H.J.; Pack, J.D. Special points for Brillouin-zone integrations. Phys. Rev. B 1976, $13,5188$. [CrossRef]

38. Mao, J.; Liu, Y.; Chen, Z.; Wang, D.; Li, Y. Bimetallic Pd-Cu nanocrystals and their tunable catalytic properties. Chem. Commun. 2014, 50, 4588-4591. [CrossRef] [PubMed]

39. Wu, J.; Shan, S.; Luo, J.; Joseph, P.; Petkov, V.; Zhong, C.-J. PdCu nanoalloy electrocatalysts in oxygen reduction reaction: Role of composition and phase state in catalytic synergy. ACS Appl. Mater. Interfaces 2015, 7, 25906-25913. [CrossRef] [PubMed]

40. Hu, Y.; Gong, H. First principles study of thermodynamic and mechanical properties of Pd $50 \mathrm{Cu} 50$. J. Alloys Compd. 2015, 639, 635-641. [CrossRef]

41. Bozzolo, G.; Garcés, J.E.; Noebe, R.D.; Abel, P.; Mosca, H.O. Atomistic modeling of surface and bulk properties of $\mathrm{Cu}, \mathrm{Pd}$ and the $\mathrm{Cu}-\mathrm{Pd}$ system. Prog. Surf. Sci. 2003, 73, 79-116. [CrossRef]

42. Wei, C.; Kong, F.; Gong, H. Phase stability and elastic property of PdH and PdCuH phases. Int. J. Hydrogen Energy 2013, 38, 16485-16494. [CrossRef]

43. Liu, J.; Fan, X.; Sun, C.Q.; Zhu, W. Layer effect on catalytic activity of Pd-Cu bimetal for CO oxidation. Appl. Catal. A 2017, 538, 66-73. [CrossRef]

44. Henkelman, G.; Uberuaga, B.P.; Jónsson, H. A climbing image nudged elastic band method for finding saddle points and minimum energy paths. J. Chem. Phys. 2000, 113, 9901-9904. [CrossRef]

45. Xu, Y.; Ruban, A.V.; Mavrikakis, M. Adsorption and dissociation of $\mathrm{O}_{2}$ on Pt-Co and Pt-Fe alloys. J. Am. Chem. Soc. 2004, 126, 4717-4725. [CrossRef] [PubMed]

46. Fouda-Onana, F.; Savadogo, O. Study of $\mathrm{O}_{2}$ and $\mathrm{OH}$ adsorption energies on $\mathrm{Pd}-\mathrm{Cu}$ alloys surface with a quantum chemistry approach. Electrochim. Acta 2009, 54, 1769-1776. [CrossRef]

47. Zhang, J.; Jin, H.; Sullivan, M.B.; Lim, F.C.H.; Wu, P. Study of Pd-Au bimetallic catalysts for CO oxidation reaction by DFT calculations. Phys. Chem. Chem. Phys. 2009, 11, 1441-1446. [CrossRef] [PubMed]

48. Tang, W.; Zhang, L.; Henkelman, G. Catalytic activity of Pd/Cu random alloy nanoparticles for oxygen reduction. J. Phys. Chem. Lett. 2011, 2, 1328-1331. [CrossRef] [PubMed]

49. Greeley, J. Theoretical heterogeneous catalysis: Scaling relationships and computational catalyst design. Annu. Rev. Chem. Biomol. Eng. 2016, 7, 605-635. [CrossRef] [PubMed]

50. Nørskov, J.K.; Bligaard, T.; Logadottir, A.; Bahn, S.; Hansen, L.B.; Bollinger, M.; Bengaard, H.; Hammer, B.; Sljivancanin, Z.; Mavrikakis, M. Universality in heterogeneous catalysis. J. Catal. 2002, 209, 275-278. [CrossRef]

51. Gómez-Marín, A.M.; Rizo, R.; Feliu, J.M. Oxygen reduction reaction at Pt single crystals: A critical overview. Catal. Sci. Technol. 2014, 4, 1685-1698. [CrossRef]

52. Nørskov, J.K.; Rossmeisl, J.; Logadottir, A.; Lindqvist, L.; Kitchin, J.R.; Bligaard, T.; Jonsson, H. Origin of the overpotential for oxygen reduction at a fuel-cell cathode. J. Phys. Chem. B 2004, 108, 17886-17892. [CrossRef]

(C) 2017 by the authors. Licensee MDPI, Basel, Switzerland. This article is an open access article distributed under the terms and conditions of the Creative Commons Attribution (CC BY) license (http://creativecommons.org/licenses/by/4.0/). 